\title{
Um Pedaço de Carne que Pensa
}

GUSTAVO BERNARDO KRAUSE ${ }^{l}$

\section{RESUMO}

A partir do corpo despedaçado do personagem Joe, do livro e do filme Johnny got his gun, de Dalton Trumbo, este artigo estuda a fragmentação da História e da Ciência na Pós-História. O conceito de Pós-História, por sua vez, formulado por Vilém Flusser, entende que Auschwitz e Hiroshima, longe de serem acidentes de percurso da racionalidade ocidental, revelaramse suas conseqüências lógicas e instituíram crise de representação tão intensa que alterou a própria noção de progresso.

Palavras-chave: Vilém Flusser; Dalton Trumbo; Pós-História. 
A História presente se vem mostrando uma história de progresso e guerras. As guerras, com o indispensável auxílio do progresso, são as piores de todos os tempos, em todos os sentidos. No início do século XXI, olhamos para a célebre foto de Robert Capa, mostrando um soldado ao ser baleado e morto na guerra civil espanhola, em 1936, e chegamos a sentir, o que é terrível, saudade - sim, porque não se morre mais assim, de peito aberto. Mata-se e morre-se pelas costas, pelo terror, pela ciência.

Como o ceticismo moderno lida com esse tempo? A pergunta exige um desdobramento: como o ceticismo moderno encara o que vem sendo chamado de "pós-moderno"?

Pode-se começar a responder recuando (muito) no tempo e recuperando a resposta de Aristóteles para a pergunta "o que é História". Segundo o Estagirita, a História conta o que de fato aconteceu, por oposição à Poesia, que conta o que poderia ter acontecido (Aristóteles, 1992, p. 53). Como se percebe, o filósofo precisou comparar a história com a poesia. No decorrer dessa mesma história, a estreita vinculação da disciplina com a narrativa, portanto com a estrutura da ficção, bem como a retomada das incertezas no século XX, puseram sob suspeita aquela distinção: quanto de poesia, isto é, quanto de invenção reside no fazer história? Como, por sua vez, a psicanálise estendeu a suspeita à própria memória humana, capaz de inventar o passado e nele acreditar com todas as forças da alma, as dúvidas sobre os chamados fatos históricos se multiplicaram e se intensificaram.

Muitos estudiosos têm posto essa intensificação das dúvidas na conta da época que chamam de pós-moderna. Há, implícita, uma espécie de saudade de uma época de certezas, época esta que, na verdade, nunca existiu - mas ao menos teriam existido pensadores, como Descartes e, mais tarde, Husserl, que se supuseram capazes de chegar à certeza. Se é correto que nunca conhecemos certezas incontestáveis, mas apenas dogmas mais ou menos categóricos, os chamados filósofos pós-modernos seriam basicamente reacionários, construindo elaborados esquemas conceituais anunciadores do apocalipse iminente, a menos que... a menos que voltemos a ser o que nunca fomos.

Para não prosseguirmos nesse caminho, precisamos descartar os conceitos de "pós-moderno" e "pós-modernidade", por entendermos que eles não solucionam os problemas com que se deparam. Dizer que algo é pós-moderno mais complica do que explica. O problema começa no prefixo e termina na raiz. Designar algo como pós-o-que-vinha-antes indicia raciocínio fraco: não se demonstra capacidade para perceber e qualificar a diferença do 
tempo que se estuda e, ao mesmo tempo, não se reconhece a própria incapacidade, obrigando-se a "construir" uma designação que parece soar como sofisticada mas, à luz de um mínimo de atenção, revela-se viciosa. Dizer que algo é pós-qualquer-coisa é o mesmo que dizer: o dia vem depois da noite e a noite vem depois do dia. Não está errado, mas e daí? Diz-se o que não se precisava dizer. Deixa-se, ainda, uma armadilha para os próprios filhos e netos: que virá depois, o pós-pós-pós?

Essa armadilha, cumpre reconhecer, se encontrava presente nos conceitos de "moderno" e "modernidade": uma época qualificar a si mesma de moderna já terá sido absurdo. Além de tautológica - somos modernos porque neste momento o somos e não poderíamos não ser - a qualificação ainda implica clara denegação do futuro; trata-se de tentativa meramente verbal de acabar com a História e declarar-se imortal. Danilo Marcondes (2001, p. 139) localiza três fontes do conceito de "modernidade": [1] ainda na filosofia medieval, um combate entre a logica modernorum contra a lógica anterior, chamada logica vetus; [2] a querela les anciens et les modernes, que agitou os meios literários franceses no final do século XVII, opondo tradicionalistas como Boileau a progressistas como Fontenelle; [3] a obra de Hegel, que elaborou, entre os séculos XVIII e XIX, pela primeira vez, uma filosofia da história da filosofia, demarcando a Idade Moderna entre os séculos XVII e XIX.

Entretanto, se somos "Os Modernos", os que nos sucederem simplesmente não serão, isto é, não nos sucederão. Cumpre reconhecer que os modernismos, com maior ou menor consciência, souberam fazer ironia do absurdo, mas com o tempo a ironia se perdeu, dando margem à... pósmodernidade.

Compreender esses conceitos como (muito) fracos não significa jogar na lata do lixo todos os teóricos que se chamam, ou que são chamados, de pósmodernos. O autor de La condition postmoderne (1998), por exemplo, escapa das dicotomias fáceis e do vale-tudo de conceito tão abrangente ao entender como pós-moderna a incredulidade em relação aos metarrelatos, compreendo as novas narrativas do saber dentro do campo da cibernética, da hipertextualidade e dos jogos de linguagem. Há aí reflexão substantiva. Jean-François Lyotard produziu estudo sem dúvida fecundo, embora sob título problemático. Infelizmente, e como seria de se esperar, popularizou-se o pós-adjetivo e não a sua análise.

O filósofo tcheco-brasileiro Vilém Flusser (1920-1991) prefere usar o conceito de "pós-história" (1983) para se referir ao momento presente, 
parecendo incorrer no mesmo problema que apontamos, e de modo amplificado: usa o prefixo vicioso "pós" sobre nada mais nada menos do que a História toda. Ora, se a História é tudo o que aconteceu e está acontecendo, o termo pós-história não faria o menor sentido, a não ser em uma concepção religiosa de outro mundo, paradisíaco ou infernal - lugares em que, como se sabe, nada mais acontecerá, exceto, respectivamente, tédio ou sofrimento permanentes.

No entanto, talvez sua concepção seja um pouco irônica - e nesse sentido, fecunda. Lembremos que os historiadores dos dias que correm já desconfiam daquela concepção da História como "tudo o que aconteceu e está acontecendo". Lembremos, também, e disto o ensino de História às vezes se esquece, que os historiadores, desde o princípio de sua profissão, falavam de uma Pré-História. A Pré-História corresponderia ao tempo que não poderia ser relatado, simplesmente porque não teriam sobrevivido relatos - em outras palavras, documentos escritos. Resta claro, então, que a História começa com a escrita e com ela se confunde. Isso significa que, se estivesse acontecendo alguma mudança substantiva com a escrita humana, com o gesto humano de escrever, passaria a fazer sentido se pensar na emergência de uma pós-História.

"História", afinal de contas, é um conceito: ocidental. Implica as noções articuladas de linearidade e progresso. A escrita ocidental é linear e progressiva - no mundo árabe da direita para a esquerda, no restante do Ocidente da esquerda para a direita, e again and again. Mas à escrita ocidental se vêm impondo tanto as imagens técnicas, cujos vetores são multilineares e multidirecionais, quanto códigos cibernéticos e hipertextuais, igualmente multilineares e multidirecionais.

A escola e a academia ainda fingem que têm fé na história, isto é, no progresso linear. A escola e a academia ainda se agarram, talvez desesperadamente, nos signos da escrita. Mas os modelos que informam a sociedade não são mais lineares nem se apóiam em vetores de mão única. Se o século XVIII via o seu ambiente como contexto de mecanismos, se o século XIX percebia o seu ambiente como contexto de organismos, nós tendemos a enxergar o nosso ambiente como contexto de jogos. Semelhante tendência para a ludicidade não é necessariamente lúdica nem divertida, pois deriva da práxis simbólica que constitui o programa: vivemos programados por programas que na verdade são jogos os quais antes jogam conosco do que os jogamos - apenas pensamos que controlamos o joystick.

Captamos a nossa existência social não como se fôssemos rodas de uma 
engrenagem, nem como se fôssemos órgãos de um corpo, mas já como peças de um jogo. Não se pergunta mais: quais as forças que movem a sociedade? Não se pergunta mais: que propósitos motivam a sociedade? A pergunta passa a ser: quais estratégias estão em jogo? É por isso que se embaralham as fronteiras entre ficção e realidade e o homem se torna: homem-metáfora - porque tudo faz parte de um jogo.

A pós-História está emergindo como conseqüência da crise da escrita mesma, logo, da verdade histórica. Essa emergência não será em si boa ou má, mas como coexiste com mentalidade arraigadamente histórica, vale dizer, progressista, parece nos deixar à beira do apocalipse. Para o filósofo praguense, não se luta contra a estupidez do progresso chamando a si mesmo de "progressista", como faz a esquerda. Luta-se contra a estupidez do progresso retardando-o ou trocando a solidão na massa pela solidão do guarda de um farol. É apenas de dentro dessa solidão que se pode diagnosticar a loucura e a estupidez que assolam o nosso tempo: um tempo que combina, explosivamente, maior democracia com muito mais ignorância.

A crença no progresso é estúpida porque implica largos antolhos, forçando-nos a olhar sempre para a frente, portanto, para a alternativa para a qual estivermos programados pela cultura e pela educação. A crença no progresso também é estúpida porque, antolhados, olhando apenas para uma direção, vemos todo obstáculo não como um recado para alterar a direção e buscar outro caminho, mas sim como um inimigo que, "logicamente", deve ser exterminado. Nesse sentido, a crença no progresso é tão responsável, tautologicamente, pelo progresso humano, quanto pela guerra de que nunca nos vemos livres. E será o mesmo progresso, agora científico, a nos ameaçar não com a pós-História, mas com o fim literal da história do ser humano no planeta Terra.

Reduzindo o argumento a uma equação simples, teríamos: a História implica o Progresso o qual, por sua vez, implica a Guerra. Logo, História = Guerra, quod erat demonstrandum.

Eis porque o que funda a pós-história, para Vilém Flusser, será Auschwitz. Auschwitz (onde foram assassinadas sua mãe e sua irmã) realiza uma das virtualidades inerentes à cultura ocidental; por Auschwitz a humanidade se reconhece como capaz do pior (por Hiroshima, em contraponto, se reconhecerá como capaz do nada). O inaudito em Auschwitz "não é o assassinato em massa, não é o crime. É a reificação derradeira de pessoas em objetos informes, em cinza. A tendência ocidental rumo à objetivação foi finalmente realizada, e o foi em forma de aparelho" (Flusser, 1983, p. 11). 
Os SS eram funcionários de um aparelho de extermínio; as suas vítimas funcionavam em função do seu próprio aniquilamento. Os SS e os judeus funcionavam uns em função dos outros, em engrenagem impessoal que até contribuiu para a derrota do nazismo - não importa. Como lembra Anatol Rosenfeld, que como Flusser fugira da Guerra para o Brasil, "o nazismo é apenas a expressão política e militante de uma atitude espiritual que não se derrota nos campos de batalha" (Rosenfeld, 1993, p.165).

O modelo, portanto, se realizou. O modelo, a partir daí, se reproduziu. O químico judeu Primo Levi, um dos poucos que sobreviveu a Auschwitz, fala disso:

"Muitos, pessoas ou povos, podem chegar a pensar, conscientemente ou não, que 'cada estrangeiro é um inimigo'. Em geral, essa convicção jaz no fundo das almas como uma infecção latente; manifesta-se apenas em ações esporádicas e não coordenadas; não fica na origem de um sistema de pensamento. Quando isso acontece, porém, quando o dogma não enunciado se torna premissa maior de um silogismo, então, como último elo da corrente, está o Campo de Extermínio. Este é o produto de uma concepção do mundo levada às suas últimas conseqüências com uma lógica rigorosa. Enquanto a concepção subsistir, suas conseqüências nos ameaçam. A história dos campos de extermínio deveria ser compreendida por todos como sinistro sinal de perigo" (Levi, 1997, p. 7).

Levi, de dentro do campo, refere-se ao lado de dentro do fim da história: "acabara o tempo no qual os dias seguiam-se ativos, preciosos e irreparáveis; agora o futuro estava à nossa frente cinzento e informe como uma barreira intransponível; para nós, a história tinha parado" (Levi, 1997, p. 119). A Solução Final - Endlösung - representou o limite do evento. Extrapolando as expectativas da sociedade que se queria civilizada e longe da irracionalidade, gerou tal acontecimento excessivo precisamente pelo abuso da racionalidade ocidental. A razão técnica quis vencer a qualquer preço e o conseguiu, pagando um preço: o horror.

O horror ainda mostrou uma outra face: a face dos aliados, a face "do bem". No dia 8 de agosto de 1945, um piloto americano pintou na fuselagem de seu avião o nome de sua mãe: Enola Gay. Depois, despejou em Hiroshima a bomba atômica que derreteu em trinta segundos cerca de cem mil pessoas. No dia seguinte, outro avião despejou outra bomba em Nagasaki e matou mais cem mil. É incalculável o número dos que morreram depois, ao longo dos anos, por efeito da radiação nuclear. Hiroshima e Nagasaki demonstra- 
ram a eficiência tecnológica anglo-saxônica. Enquanto os nazistas seriam "loucos", matando em nome de um ideal psicótico, a bomba americana foi lançada em nome da "Razão". Assim como os nazistas elaboraram uma lógica burocrática para a "solução final", os americanos criaram uma lógica científica para seu crime.

A despeito, alguns escritores tentaram falar do horror com os instrumentos da ficção, entre eles o próprio Primo Levi, com É isto um homem? (1997), e, mais recentemente, Bernhard Schlink, com O leitor (1998). Mas supomos que nenhuma narrativa tenha revolvido tanto o fundo do problema quanto o romance cujo acontecimento principal ocorre no último dia da Primeira Guerra Mundial, e que, paradoxalmente, foi publicado precisamente dois depois de Hitler invadir a Polônia, marcando o começo da Segunda Guerra Mundial - escrito quando a América ainda não sabia direito de Auschwitz e ainda não se desenhara a bomba de Hiroshima.

Trata-se de Johnny got his gun (1939), de Dalton Trumbo (1905-1976).

$*$

O americano James Dalton Trumbo publicou os romances: Eclipse (1935); Washington Jitters (1936); Johnny got his gun (1939); The remarkable Andrew (1940); Chronicle of a literal man (1941); e Night of the Aurochs (1979 - edição póstuma). Mas se destacou principalmente como roteirista. É autor do roteiro de 76 filmes, incluindo Papillon (1973), Exodus (1960), Spartacus (1960), e The brave one (1956 - Oscar de Melhor Roteiro).

Alguns dos seus principais roteiros, inclusive o de The brave one, foram creditados aos pseudônimos Jack Davis ou Robert Rich, em função da perseguição que o autor sofreu do maccarthismo. Trabalhou como ator em quatro filmes, entre eles Papillon (como o comandante). E dirigiu apenas um filme, em 1971, exatamente a adaptação do seu romance Johnny got his gun.

Trumbo era indispensável para Hollywood, por escrever os roteiros de maneira rápida e prontos para serem levados à cena. Mas Trumbo também foi uma ameaça para o establishment americano, fazendo parte dos Hollywood Ten, grupo de escritores, diretores e produtores que manteve a integridade perante os interrogatórios públicos daquele tempo (os outros nove foram: Alvah Bessie, Lester Cole, John Lawson, Ring Lardner Jr, Herbert Biberman, Adrian Scott, Samuel Ornitz, Albert Matz e Edward Dmytryk).

Em 1947, Dalton Trumbo foi condenado a um ano de prisão por "ativi- 
dades anti-americanas". A leitura do seu interrogatório perante a Comissão mostra-o inflexível, não revelando nada sobre os amigos - a declaração que preparou acabava com estas palavras: this is the beginning of an American concentration camp - "esse é o começo de um campo de concentração americano" (em Hanson, 2001, p. 92). Depois da prisão, exilou-se por algum tempo no México, onde continuou a escrever, sob pseudônimo, os seus argumentos.

De que trata o livro Johnny got his gun? Trata-se, a juízo de muitos, inclusive nosso, do mais belo e terrível romance escrito contra a guerra, em qualquer época. O personagem central é um jovem soldado mutilado no último dia da I Guerra Mundial. Ele não foi atingido por um tiro, como o soldado de Capa (o próprio Robert Capa morreu vitimado por uma mina terrestre), mas por uma granada, que fez com que ele perdesse as duas pernas, os dois braços, e toda a face (olhos, ouvidos, nariz, boca). Joe Bonham, o soldado, é mantido vivo, para estudos, porque acreditam que ele não mais pensa. Só que ele pensa, sonha e sofre, "vivendo" assim por vários anos, reconhecendo, aos poucos, que se tornou um pedaço de carne com a mente intacta: he was thinking and he was just a thing (Trumbo, 1994, p. 84).

Apesar de se tratar de um johnny, qualquer semelhança com as experiências nazistas, portanto com Auschwitz, não é mera coincidência. O que é feito com Joe, em nome da defesa da democracia, mutilando-o na guerra, e em nome da ciência, mantendo-o vivo para observar melhor um homem-que-não-é-um-homem, um homem que perdeu toda fala, toda mobilidade e, pensavam os médicos, toda capacidade de pensar e sentir, encontra-se perfeitamente dentro da lógica da História, isto é, da lógica do progresso.

Diz Trumbo, sobre sua história:

"the devil I am trying to catch, is that dark yearning for power that lurks in all of us, the perversion of love that is the inevitable consequence of power, the exquisite pleasures of perversion when power becomes absolute, and the dread realization that in a time when science has become the servant of politics-as-theology, it can happen again".

Ou seja:

"o diabo que estou tentando capturar é este sombrio anseio por poder que espreita em todos nós, a perversão do amor que é a conseqüência inevitável do poder, o raro e perverso prazer que emerge quando o poder se torna 
absoluto, e a pavorosa realização que se dá no tempo em que a ciência se tem tornado serva da política-como-teologia - e isso pode estar acontecendo novamente..."

Com o personagem Johnny, Trumbo criou o arquétipo "vivo" do Soldado Desconhecido, falando de um Zé-Ninguém que representa Todo-Mundo. O livro, publicado em momento delicado, não foi reconhecido imediatamente. Mas se torna sucesso editorial a partir de 1959, influenciando a geração emergente dos beatniks e de cada cantor de protesto, como Bob Dylan. Tornou-se referência obrigatória nos movimentos pacifistas americanos, em especial na Guerra do Vietnam. Tornou-se, também, por incrível que nos pareça, um clássico, adotado com freqüência nas high schools dos Estados Unidos.

No prefácio à edição de 1959, Trumbo escreve que o seu livro tem uma estranha história política. Escrito em 1938, quando o pacifismo era um anátema para a esquerda americana, acabou sendo publicado em 1939, exatamente dois dias depois de começada a Segunda Guerra Mundial. Houve algumas tentativas de censura, como comenta Paul Blanshard, no livro The right to read (1955):

"a few pro-Axis foreign-language magazines had been banned, as well as three books, including Dalton Trumbo's pacifist novel Johnny get your gun, produced during the period of the Hitler-Stalin pact" - "umas poucas revistas estrangeiras pró-Eixo teriam sido banidas, assim como três livros, incluindo o romance pacifista de Dalton Trumbo, Johnny get your gun, produzido durante o período do pacto Hitler-Stalin" (em Trumbo, 1994, p. 3).

Mr. Blanshard, segundo Trumbo, teria cometido três erros: no título do livro, no período em que o livro foi escrito, e na própria suposição de censura e banimento do livro. Certamente a obra esteve sob suspeita e ajudou no processo contra o autor, em 1947, mas nunca chegou a ser "banida". Depois de duas ou três edições, o livro esteve fora de catálogo durante a Guerra da Coréia e é reeditado exatamente no começo da Guerra do Vietnam, em 1959. Esta guerra durou até 1975 . O povo americano e o mundo entenderam a retirada dos Estados Unidos como uma derrota fragorosa: as imagens de pessoas desesperadas no teto da embaixada americana tentando uma última vaga nos helicópteros marcaram na mente de todos a retirada caótica de um exército que se queria o mais poderoso do mundo. Johnny, assim, cujo 
episódio central se teria passado no último dia da Primeira Guerra Mundial, ia acumulando significados e perplexidades no decorrer dessas três guerras - e, depois, das que se lhe seguiram no final do século XX e no início assustado(r) do século XXI.

Na edição de 1970, Trumbo acrescenta adendo irônico e muito mais indignado:

"Eleven years later. Numbers have dehumanized us. Over breakfast coffee we read of 40.000 American dead in Vietnam. Instead of vomiting, we reach for the toast. Our morning rush through crowded streets is not to cry murder but to hit that trough before somebody else gobbles our share. An equation: 40.000 dead young men $=3.000$ tons of bone and flesh, 124.000 pounds of brain matter, 50.000 gallons of blood, 1.840 .000 years of life that will never be lived, 100.000 children who will never be born (the last we can afford: there are too many starving children in the world already). Do we scream in the night when it touches our dreams? No. We don't dream about it because we don't care about it. We are much more interested in law and order, so that American streets may be made safe while we transform those of Vietnam into flowing sewers of blood which we replenish each year by forccing our sons to choose between a prison cell here or a coffin there. 'Every time I look at the flag, my eyes fill with tears'. Mine too" (Trumbo, 1994, p. 8).

Os números desumanizam: no café da manhã lê-se sobre os quarenta mil americanos mortos (até então) na Guerra do Vietnam e, ao invés de vomitar, pegamos mais uma torrada. Trumbo faz a conta do que representam quarenta mil jovens mortos, em termos de carne, osso, sangue e matéria cerebral - em termos de anos de vida que nunca serão vividos e de crianças que nunca nascerão (mas não faz mal, ironiza, se já haveria crianças famintas demais nesse mundo). Os americanos sonhariam com esses números? Não. Eles não estariam preocupados com isso, mas sim com a manutenção da lei e da ordem nas ruas americanas enquanto se transformam os caminhos vietnamitas em esgotos cheios de sangue nos quais seus filhos deveriam mergulhar, escolhendo entre a prisão "aqui" ou o túmulo "lá". Invoca uma sentença tipicamente patriótica e piegas, "quando olho para a bandeira, meus olhos se enchem de lágrimas", acrescentando que os olhos dele também se enchem de lágrimas - mas o contexto torna a sua afirmativa irônica, desvalorizando, através da bandeira, a noção de "pátria", capaz de mandar tantos matarem e se matarem em nome de abstrações. 
Trumbo a seguir se pergunta, perguntando ao leitor e a seus compatriotas, se sabem sobre os mortos, se sabem sobre os seus johnnies, quantos estariam cegos ou mutilados, imóveis até o resto dos seus dias, vegetais descerebrados respirando quietos em mínimos e escuros quartos secretos:

"Does anyone know where they are? How they feel? How many arms, legs, ears, noses, mouths, faces, penises they've lost? How many are deaf or dumb or blind or all three? How many are single or double or triple or quadruple amputees? How many will remain immobile for the rest of their days? How many hang on as decerebrated vegetables quietly breathing their lives away in small, dark, secret rooms?" (Trumbo, 1994, p. 9).

Na edição de 1991, há um outro prefácio precioso, escrito por Ron Kovic. Kovic acabara de voltar paraplégico da guerra do Vietnam e se tornado tema de um filme de Oliver Stone, Born on the Fourth of July (1989), seu personagem tendo sido interpretado por Tom Cruise. Kovic escrevera, junto com Oliver Stone, o roteiro de Nascido em 4 de Julho. Na primavera de 1971 Kovic escutara, numa demonstração contra a guerra em Los Angeles, o ator Donald Sutherland, ao lado de Jane Fonda, ler trechos de Johnny got his gun. A partir daquele momento, o livro se tornara um divisor de águas para ele, uma espécie de timebomb of truth que caíra na sua vida. Comparando-se a Joe Bonham, entendeu que ambos teriam sacrificado seus corpos em uma guerra sem sentido - mas precisavam dar sentido ao que lhes acontecera. Joe quis pegar a sua arma - seu próprio corpo mutilado - e apontá-lo, como a melhor de todas as armas, contra a guerra. Ele poderia fazer algo equivalente, tornando-se, e à sua condição, instrumento de paz, apesar e por ter sido produto da guerra. Assim, o mundo poderia, quem sabe, mudar, a Razão substituindo o Absurdo:

"Suddenly, I saw that I could be an instrument of peace. I could use my body and my experiences as awful and tragic as they were to educate others about war, its futility and absurdity, its senselessness and waste, just like Joe Bonham. I could parade myself around America so they would see war once and for all for what it really was. I would take my injury, both physical and emotional, and as horrifying as it might be, make it an instrument of learning and enlightenment; and somehow, if I was lucky, the world would change, sense would replace nonsense" (em Trumbo, 1994, p. XV).

Quando Ron Kovic se encontrou com Dalton Trumbo, the pediu que autografasse sua cadeira de rodas. Trumbo escreveu nas costas da cadeira: 
Nothing more can be said - it can only be done. Então, assinou o seu nome (em Trumbo, 1994, p. XIV). É compreensível que Trumbo escrevesse essa frase, como se negasse a partir daí a própria literatura: ele acabava de se encontrar com seu próprio personagem. Logo, tudo parecia ter sido escrito para se coroar naquele momento, naquele encontro.

O título da obra de Dalton Trumbo é uma resposta a popular refrão patriótico que convocava os jovens para a guerra: Johnny get your gun! (explica-se o erro de Mr. Blanshard: o refrão nunca saíra da sua cabeça). O Johnny em questão seria um produto da "idade da inocência", uma geração educada para viver na ignorância da História. Johnny era o jovem americano, saudável, idealista, ignorante, pronto para experimentar o mundo como tão-somente o reflexo de si mesmo e de seus compatriotas.

A história de Johnny vai do cômico ao patético, do patético ao trágico, do trágico ao humor negro, e do humor negro à máxima compaixão pelo ser humano. Para o leitor, Johnny se torna um herói, talvez o maior de todos anos a fio, páginas e fotogramas a fio, o personagem imaginava uma maneira de se comunicar com o mundo exterior, mundo este que, ou não sabia da sua existência, ou o considerava apenas um pedaço de carne, sem pensamentos ou sentimentos, que se podia manter vivo para "experiências".

Finalmente consegue pensar em bater a cabeça, o único movimento que lhe restou, no travesseiro, mas em código morse, para se comunicar com a enfermeira. Mas enfermeiras se sucedem sem perceber que aquela "coisa" estava tentando se comunicar, entendendo que havia apenas um reflexo nervoso a ser aplacado com sedativo. Johnny, todavia, não desiste e continua tentando, "teclando", em Morse, S.O.S., S.O.S., S.O.S., S.O.S., S.O.S. ..., até que uma enfermeira nova finalmente parece compreender.

Ela chama Tillery, o coronel-médico que o internou, agora um velho general que se faz acompanhar de outro general, de um oficial de comunicações e de um capelão. O oficial reconhece o pedido de socorro. No filme, o general olha para o médico e pergunta: decerebrated, general? Completely decerebrated? O velho médico sai da sala, mancando (ele também era um mutilado de guerra, apoiado em muletas), o rosto uma máscara de desespero misturada à arrogância de sempre.

O oficial, batendo com os dedos na testa do paciente, pergunta: what do you want? O que Joe pensa nesse momento, expresso detalhadamente no capítulo XIX do romance, é muito simples, mas a simplicidade dói. O que ele deseja? Ora: 
"He wanted eyes to see with. Two eyes to see sunlight and moonlight and blue mountains and tall trees and little ants and houses that people live in and flowers opening in the morning and snow on the ground and streams running and trains coming up and going and people walking and a puppy dog playing with an old shoe worrying it and growling at it and backing away from it and frowning and wiggling its bottom and taking the shoe very seriously. He wanted a nose so that he could smell rain and burning wood and cooking food and the faint perfume that stays in the air after a girl has passed by. He wanted a mouth so he could eat and talk and laugh and taste and kiss. He wanted arms and legs so he could work and walk and be like a man like a living thing" (Trumbo, 1994, p. 283).

\section{Apenas:}

“olhos para ver 'o nascer e o pôr do Sol e as montanhas azuis e as árvores mais altas e as menores formigas e as casas onde as pessoas vivem e as flores se abrindo de manhã e a neve sobre a terra e os riachos correndo e trens indo e vindo e um filhote brincando com um sapato velho atacando-o e rosnando e pegando-o por trás e franzindo o focinho e sacudindo-o por baixo e trazendo-o muito sério'; um nariz para sentir 'o cheiro da chuva e da madeira queimando e da comida cozinhando e do tênue perfume que permanece no ar depois de uma garota ter passado por ali', uma boca com a qual ele pudesse 'comer e falar e rir e provar e beijar'; enfim, ele desejava 'braços e pernas com que ele pudesse trabalhar e caminhar e ser como um homem vivendo algo como uma vida".

\section{Somente.}

O que ele deseja, não é possível? Não. E ele sabe. Por isso, o que ele pede é outra coisa. Ele esteve deitado ali por anos e anos, mas naquele momento ele queria algo ainda simples: sair dali para ficar no meio de pessoas, no meio de gente. No filme, ele pede para que o exibam numa espécie de carnival show, onde ele possa sentir a trepidação de pessoas à sua volta, ainda que não as escute ou veja ou perceba seu cheiro.

O seu pedido desesperado tinha, ao mesmo tempo, um significado político, como o romance explicita:

"He would be an educational exhibit. People wouldn't learn much about anatomy from him but they would learn all there was to know about war. That would be a great thing to concentrate war in one stump of a body and to show it to people so they could see the difference between a war that's in 
newspaper headlines and liberty loan drives and a war that is fought out lonesomely in the mud somewhere a war between a man and a high explosive shell. Suddenly he took fire with the idea he got so excited over it he forgot about his longing for air and people this new idea was so wonderful. He would make an exhibit of himself to show all the little guys what would happen to them and while he was doing it he would be self-supporting and free. He would do a favor to everybody including himself. He would show himself to the little guys and to their mothers and fathers and brothers and sisters and wives and sweethearts and grandmothers and grandfathers and he would have a sign over himself and the sign would say here is war and he would concentrate the whole war into such a small piece of meat and bone and hair that they would never forget it as long as they lived" (Trumbo, 1994, p. 287).

Ele queria ser publicamente exibido como the dead-man-who-is-alive, o homem-morto-que-está-vivo, ou, significando o mesmo, the live-man-whois-dead: o homem-vivo-que-está-morto. A exibição pública do seu corpo destroçado, do seu corpo despedaçado, seria pedagógica, educativa, dizendo: "vejam, esse não-homem é um produto da guerra; esse não-homem é a guerra". Ele queria ser publicamente exibido numa caixa de vidro em todas as escolas, universidades, academias, parlamentos e igrejas. Ainda que as crianças e seus pais tivessem pesadelos, os teriam com a guerra, para que tais pesadelos se tornassem antídotos contra os estúpidos sonhos do progresso, do heroísmo e do nacionalismo. Ele seria the man who made the world safe for democracy, transformando a ironia que percorrera todo o romance em uma possibilidade não-irônica.

Quando criança, Joe perguntara ao pai, o que é democracia? O pai the respondera, filho, "democracia é um tipo de governo que faz com que os jovens se matem entre si". Joe rememora (ou delira) essa conversa com o seu pai, que mostra como o Joe-Ninguém tem um pai igualmente JoeNinguém (a representar, também, Todo-Mundo), mas lúcido a respeito da sua condição, que na verdade metaforiza a condição humana:

"JOE'S FATHER: Nothing I have in this world is really any good, you know. My house is small, my job is small. My salary is also small. Son is small, so is my wife and, when you get right down to it, I'm no giant myself. Everything around me is small, inferior - except this fishing pole. I myself wind it every year with the best silk thread. See this lacquer? Comes from China. No finer lacquer in the world. See those guides? Pure amber. 
Nobody in town has a fishing pole like this. Not even Mr Latimer down at the bank. My life is so poor and shoddy that, without this pole, I'd have nothing to set me apart from other men. Nothing to give me distinction. Nothing at all. That's why I love it so much.

YOUNG JOE: Do you love it more than you love me?

JOE'S FATHER: Ha, ha! Of course I do. What is there about you that can give a man distinction? You're not unusual at all.

YOUNG JOE: Yes I am, father.

JOE'S FATHER: How's that?

YOUNG JOE: I may not be unusual now, but I'm going to be.

JOE'S FATHER: Of course you are. Gonna make the world safe for democracy, are you?

YOUNG JOE: What's democracy?

JOE'S FATHER: Well, I was never very clear on that myself. Like every other kind of government, it's got something to do with young men killing each other, I believe...

YOUNG JOE: When it comes my turn - will you want me to go?

JOE'S FATHER: For democracy, any man would sacrifice his only begotten son" (em Hanson, 2001, p. 191).

A conversa sobre uma antiga e preciosa vara de pescar remete a questões como guerra, responsabilidade e mortalidade, a partir do reconhecimento de uma identidade pessoal pequena: "minha casa é pequena, meu trabalho é pequeno. Meu salário é igualmente pequeno. O filho é pequeno, também minha mulher, e enfim, eu mesmo não sou um gigante. Tudo à minha volta é pequeno, inferior - exceto minha vara de pescar".

Nessa conversa é que se definiu "democracia". Trumbo borra a linha que separa o flashback da alucinação e põe sob suspeita todas as grandes palavras, como "democracia" e "amor". O pai de Joe mostra-se também sábio, mas do tipo cínico, sabendo que se distingue dos demais tão-somente por uma vara de pescar - mesmo seu filho é um filho-Ninguém: paradoxalmente, se tornará Alguém quando morrer na guerra, como Herói, ou quando desaparecer na mesma guerra, como Soldado Desconhecido a serviço do imaginário nacional e nacionalista (secretamente, e entre parênteses, a serviço da Ciência).

Mas esse Soldado Desconhecido tem um corpo (embora não tenha braços nem pernas) e tem um rosto (embora não tenha uma face). Se ele, o homem-morto-que-está-vivo, fosse exposto, a verdade seria exposta nua e 
crua - tronco vivo sem braços, sem pernas, sem face. Nesse caso, o termo "democracia" perderia sua condição irônica, para recuperar um sentido perdido.

Conseqüentemente, naquele quarto, o oficial de comunicações finalmente responde a seu pedido para ser exibido, "teclando" em código Morse na sua testa e terminando com os muitos anos daquele isolamento mais do que absoluto. A resposta, no entanto, não é a que ele queria, embora o leitor a pudesse prever:

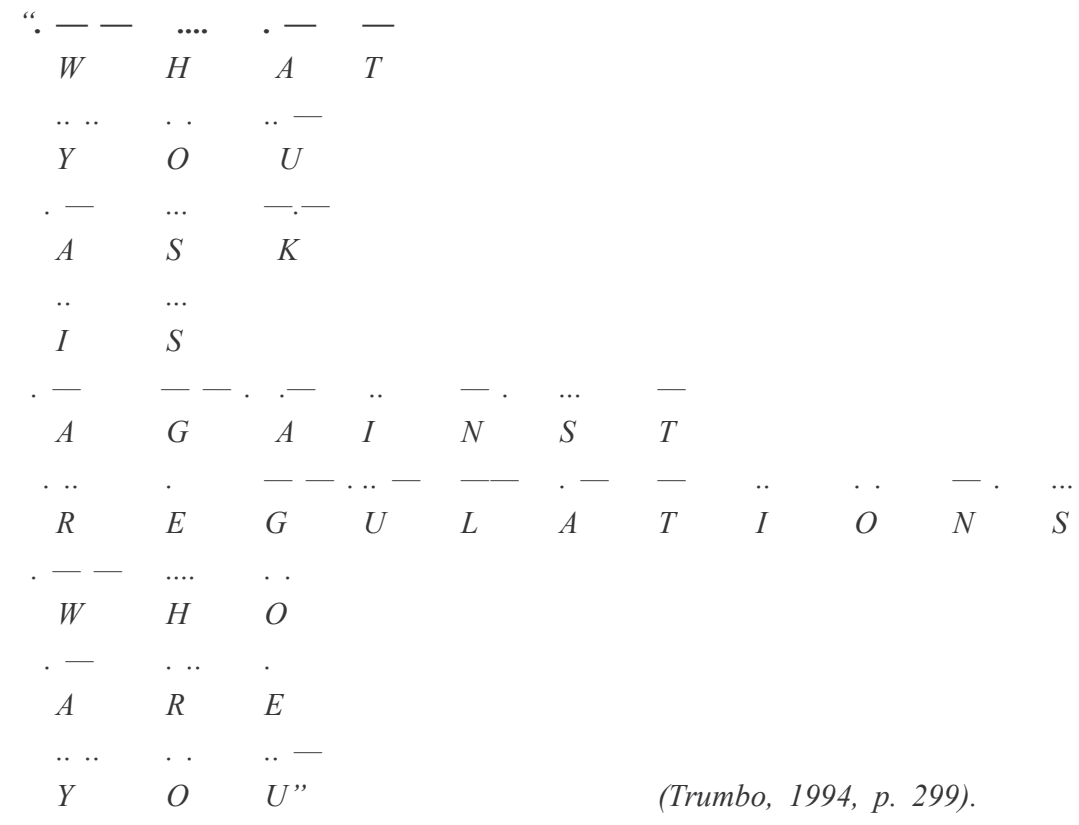

Não sabiam o nome do Soldado Desconhecido e continuariam sem saber, mas responderam a seu pedido desesperadamente lúcido da maneira mais militar possível: "o que você pede é contra as normas". Porque:

"He was the future he was a perfect picture of the future and they were afraid to let anyone see what the future was like. Already they were looking ahead they were figuring the future and somewhere in the future they saw war. To fight that war they would need men and if men saw the future they wouldn't fight. So they were masking the future they were keeping the future a soft quiet deadly secret. They knew that if all the little people all the little guys saw the future they would begin to ask questions" (Trumbo, 1994, p. 306).

Porque: "ele era o futuro ele era o retrato perfeito do futuro e eles tinham 
medo de deixar qualquer um ver com o que o futuro se parecia". "Eles" viam no futuro sempre outra guerra e mais outra, e para essas guerras que sempre se avizinhavam eles precisavam de homens e se os homens vissem o futuro eles poderiam não lutar. Então, eles estavam disfarçando o futuro, transformando-o em um segredo mortal: "eles sabiam que se todas as crianças e se todos os jovens vissem o futuro eles poderiam começar a fazer perguntas" - e não se podem admitir perguntas sobre a guerra.

No filme, Joe pede então para ser morto - please, kill me -, mas isso também era contra as normas. Ele não podia sequer se suicidar, porque não tinha mãos e porque "respirava" por um tubo direto na sua traquéia. Ele não podia nem mesmo tentar prender a respiração até morrer. A morte estava fora do seu controle. A vida estava fora do seu controle. O horror o controla. O horror nos controla, a cada vez que começa uma pequena ou uma grande guerra. Em nome da democracia, em nome do povo, em nome da liberdade, ou mesmo em nome de Deus, esconde-se o nome verdadeiro do Horror.

No filme, o general pede ao capelão que diga umas palavras de fé e consolo para Johnny. O capelão lhe responde que rezará por ele e pensará nele até o fim dos seus próprios dias, mas que não pode consolar o que não tem consolo, não pode dar esperança a quem não tem por que ter nenhuma esperança, nem mesmo em Deus. O general critica o capelão por não fazer o seu serviço, mas este responde ao general: "ele é um produto da sua profissão, não da minha".

Quando saem todos do quarto, a enfermeira (representada por Diane Varsi) que afinal o compreendera, chorando, tenta atender a seu pedido final, bloqueando seu tubo de respiração. Joe, comovidíssimo, lhe agradece em pensamento - mas o general retorna na hora, vê o que está acontecendo e "salva" Joe. A enfermeira é obrigada a sair do quarto, devolvendo a chave. Nosso personagem percebe que ele está morto para sempre, isto é, que ele está vivo "para sempre" - ele agora é definitivamente um segredo de guerra.

Vivo, ele não vive. De fato, ninguém vive - nem Deus. Porque não pode haver nenhum Deus. Então ele bate com a cabeça, sem parar, "teclando" S.O.S., S.O.S., S.O.S., S.O.S., S.O.S. ...

Em 1961, Dalton Trumbo e Luís Buñuel redigiram juntos o roteiro para o filme, que seria dirigido pelo espanhol. Como o produtor faliu, o projeto foi 
engavetado, sendo retomado apenas em 1971. O filme é dirigido então pelo próprio Dalton Trumbo, recebendo o Prêmio Especial do Júri de Cannes, no mesmo ano.

Quando viu o filme, mais tarde, Buñuel ficou entusiasmado, escrevendo a Trumbo: "Eu gostei imensamente de Johnny. Encontrei no filme a força do romance, todo o seu efeito devastador, com momentos de imensa emoção. A escolha do ator é simplesmente extraordinária: sua inocência e sua juventude acentuaram o sentimento de inexorabilidade de seu destino. A impressão deixada pelo filme é uma das mais fortes que já terei sentido" (esse comentário de Buñuel está publicado no caderno que acompanha a versão francesa, em DVD, de Johnny got his gun - Johnny s'en va-t-en guerre").

$\mathrm{O}$ ator que representou Joe Bonham chamava-se Timothy Bottoms. Livro e filme se complementam. No livro a história é contada, não no ponto de vista (por que ele não vê...), mas como que pela mente do soldado. Embora se passem muitos anos com o personagem naquelas condições - escuro e silêncio absolutos, sem interação possível com outros seres humanos - ele continua pensando, e portanto narrando a história, como um adolescente extremamente ingênuo que, por isso mesmo, aos poucos oferece ao leitor sínteses iluminadoras da condição da humanidade. A sintaxe do seu pensamento se apóia, como vimos nos trechos citados, em um fluxo de consciência fragmentado que monta mosaico transparente da sociedade e da guerra.

No filme, a câmera mostra, em preto e branco, as discussões entre generais, médicos, padres e enfermeiros, revelando, em imagens coloridas, as lembranças, os sonhos e as reflexões do protagonista. $\mathrm{O}$ ator mais conhecido do filme era Donald Sutherland, no papel de Jesus Cristo - um Cristo extremamente cético que aparecia nos sonhos de Johnny. Seu comportamento, irônico e desesperançado, parece remeter a célebre provocação do anarquista russo Mikhail Bakunin: "se Deus aprova a guerra, então Deus, se realmente existe, deve ser abolido". Numa das mais belas cenas do filme, Cristo é o maquinista de um trem que carrega os mortos da guerra: cabelos ao vento, se assemelha justamente a um dos cavalheiros do Apocalipse ou à própria Morte, substituindo-se o cavalo pela locomotiva.

O filme passou pouco tempo no Brasil, sob o título de Johnny vai à guerra - a tradução do título, embora não seja literal, é boa, porque não temos familiaridade com aquele refrão patriótico, e porque acaba por remeter ao final do romance, quando Joe, através de código Morse, consegue se comunicar: ele pede para ser exposto em praça pública, como parte de uma 
verdadeira guerra visual contra todas as guerras. Expondo sua monstruosidade, Johnny queria dizer: vejam, a guerra é isso. A arma de Johnny seria, na verdade, ele mesmo - a exibição pública da sua condição. Ele não foi à guerra, agora é que ele está indo à guerra contra a guerra, à guerra contra o progresso fetichizado e, portanto, desumanizado, à guerra contra a hipocrisia da democracia e, principalmente, à guerra contra os mestres e os doutores da guerra.

Quem quer que tenha assistido a esse filme no cinema experimentou a dificuldade de ir a um barzinho depois, mas não porque o diretor tivesse caprichado no realismo das cenas de combate e de sangue. A câmera narrativa, na verdade, é muito contida, apenas sugerindo o horror, sem jamais mostrar, por exemplo, o não-rosto do personagem.

A atmosfera criada pelo jogo preto-e-branco e cores, invertendo o clichê do gênero - costuma-se usar o preto-e-branco para o passado, ou para o sonho, e o colorido para o presente, ou para a realidade, mas Trumbo fez exatamente o contrário - forçava o espectador não a chorar, que a história não se dá de maneira piegas, mas a não conseguir soltar o choro da garganta e da mente. Em outras palavras: tanto livro quanto filme ficam engasgados.

Alguns críticos consideram esse filme o maior filme pacifista de todos os tempos; outros, como Peter Hanson, entendem que ele pode ser considerado o tosco rascunho de um grande filme - "it can rightly be called the rough draft of a great movie" (Hanson, 2001, p. 185). Haveria cenas repetitivas e desnecessárias, narração monótona e várias seqüências fantasiosas e "pedestres", isto é, óbvias. O famoso crítico de cinema Leonard Maltin considera a película uma "mórbida versão do romance de Trumbo que, apesar de tocante na abertura e no clímax, mostra que everything in the middle is either talky, pretentious, or amateurish - "tudo no meio é ou palavroso, ou pretensioso, ou amador" (em Microsoft Cinemania 97).

As críticas nos parecem motivadas pelo fato de este ser o primeiro e único filme dirigido por Trumbo, e já em idade avançada, predispondo os críticos a enxergar inexperiência (ou senilidade) - no caso específico de Maltin, aquela avaliação arrasadora seria motivada, ainda, por sua postura política, digamos, "patriótica". A nosso entender, as críticas são equivocadas, por não perceberem que, desde o livro, o ponto de vista é o de um adolescente americano médio que acreditava na democracia e nos seus heróis, justificando a repetição de cenas tão "pedestres" quanto o personagem.

Numa cena que parece misturar memória com delírio, Joe menino beija a mãe na cozinha, num dia de inverno, e depois vai cumprimentar os animais 
de estimação, que se aquecem atrás do fogão de lenha: o cão peludo, o gato amarelo, um rato branco e vários pintos numa caixa. A cena é muito rápida, mas a coexistência de todos esses animais sugere, de acordo com a mentalidade e as metáforas possíveis para o próprio Joe, a paz que não vigora entre os seres humanos.

Além disso, os críticos parecem se esquecer de que o roteiro do filme foi escrito, em 1961, a quatro mãos, com ninguém menos do que Luís Buñuel, ou seja, o mais surrealista dos cineastas. Grande parte do impacto do filme advém justamente dessa combinação entre a concepção surrealista e uma perspectiva cliché do mundo. A combinação quebra, de dentro do código cinematográfico, as pressuposições do espectador e o conforto do lugarcomum.

Há cenas antológicas, como quando, no começo, o personagem se recorda do dia anterior ao que embarcara para a guerra, e a alucinada conversa entre Joe e Jesus.

Na primeira cena, Joe está com sua namorada no sofá da sala, no escuro. Enquanto se abraçam, ela tenta convencê-lo a não ir, certa de que vão matá-lo. Ele, garantindo que vai voltar, abraça-a com mais força. De repente o pai da menina chega e acende a luz. Manda a filha para o quarto - logo em seguida, diz para o rapaz ir também. Eles ficam espantados, mas vão. A profunda tristeza do pai, personagem que aparece no filme em menos de um minuto, indica que ele é um sábio, porque ele sabe: sua filha está virando mulher, e isso deve ser protegido. Mas sabe mais: o homem que ela ama não vai voltar; ele vai morrer - mais uma razão para que ele proteja, dolorosamente, a despedida dos dois namorados.

No entanto, acontecerá algo pior ainda: ele não vai voltar, mas não vai morrer. Só que isso eles não sabem e não saberão. A cena de amor que se segue no quarto contrastará fortemente com o restante do filme: a guerra e a mutilação provocada pela guerra. Para preparar a cena, Kareen, a namorada, se olha no espelho, que reflete três imagens, três camadas: as pequenas sapatilhas de balé, nos contando da garotinha que ela era até aquela noite; o rosto de Kareen, sorrindo nervosamente e nos contando da mulher que ela se encontra prestes a se tornar; e Joe, imóvel ao fundo, mostrando-nos o que liga as duas partes da vida de Kareen. As três imagens combinadas através do espelho - através da representação cinematográfica - emprestam à cena uma intimidade muito forte, fazendo com que o ritual desajeitado que se segue, ao tirarem as roupas, se aproxime do sublime.

A conversa alucinada entre Joe e Jesus se dá numa carpintaria, onde 
Cristo fabrica enormes cruzes brancas. Joe pede ao outro para the dizer a diferença entre realidade e fantasia, porque ele não sabe se um rato, no hospital, está passeando pelo seu corpo e o roendo, ou se seria um mero pesadelo. Na verdade, ele tem a sensação de que a sua condição mutilada é tão horrível que só poderia, que só deveria ser apenas um pesadelo. $\mathrm{O}$ Cristo, representado por Donald Sutherland, responde tentando the ensinar a não ter pesadelos:

"CHRIST: Maybe the thing to do is police your mind before you go to sleep. Say to yourself: "I'm going to sleep now - and I'm not going to have any nightmares". Could be done, you know - with practice. If you feel yourself getting drowsy -

JOE: I never feel drowsy. I haven't got any thing to feel drowsy with.

CHRIST: Nothing?... Maybe we should take a different line of attack altogether. Let us begin by assuming that everything is a dream, which, by and large, it is. When we're awake, we have one kind of dream. When we've asleep, we have another. The difference is that we control our daydreams. And the dream that comes to us at night controls us".

Seria preciso que Joe policiasse a mente antes de dormir, dizendo a si mesmo que está indo dormir e que não terá pesadelos. Mas Joe não tem como saber que vai dormir ou está dormindo, não tem como se perceber sonolento. Então Cristo sugere assumir que tudo é um sonho: quando estamos despertos, temos um tipo de sonho, quando acordados, outro. A diferença entre eles é que, enquanto controlamos nossos sonhos de dia, os sonhos da noite nos controlam.

Logo, quando o rato passear pelo seu corpo, Joe deve tentar afastar o rato, com um chute ou com um tapa. Se ele não conseguir, é porque está dormindo e o rato é apenas parte de um sonho ruim. Joe argumenta que a experiência não vai funcionar, porque o seu corpo vivo não tem braços para dar um tapa ou pernas para dar um chute. Cristo então se irrita, já que nenhuma das suas sugestões parece funcionar para aquele rapaz:

"CHRIST: Since your real life is a greater nightmare than your dreams, it would be cruel to pretend that anyone could help you. What you need is a miracle.

JOE: No, not a miracle. Just tell me that the rat is real, and the way I am now is a dream.

CHRIST: Perhaps it would be better for you to go away now. You're a very unlucky young man, and sometimes it rubs off.

JOE: I'll go, but first tell me just one thing - are you and I really here together, or 
is this just a dream, too?

CHRIST: It's a dream.

JOE: How do you know?

CHRIST: Because I'm a dream.

JOE: I don't believe you.

CHRIST: Nobody does. That's why I'm as unreal as every other dream that didn't

come true" (em Hanson, 2001, p. 192).

Como se vê, o Cristo de Trumbo, que parece não ter coragem de encarar Joe, no sonho, entende não só que ele mesmo é um sonho como ainda que a realidade é um outro tipo de sonho que supostamente controlaríamos. O Cristo de Trumbo se irrita com a impotência de Joe, revelando sua própria impotência. Fala que o outro precisa é de um milagre, "como se" milagres fossem impossíveis... A ironia é clara e se reforça com a ambigüidade do diálogo final: Cristo diz que ele mesmo é um sonho e Joe responde que não acredita nele, ou seja, não acredita que Jesus Cristo seja apenas um sonho, mas o Nazareno do pesadelo retruca, nobody does, isto é, ninguém acredita Nele - "eis porque eu sou tão irreal quanto qualquer outro sonho que não se tornou realidade".

Há ainda uma outra cena delirante, em que o patrão de Joe na padaria canta "I'm the boss, merry christmas" ene vezes, enquanto seus empregados dançam como se fossem bonecos de madeira. De repente, entra pela porta uma mulher negra, velha e manca, típica ex-escrava norte-americana, procurando seu filho, que não acha em lugar nenhum - o filho se chamava Jesus Cristo... Esta cena, para os críticos comentados, seria certamente dispensável, mas numa perspectiva surrealista o dispensável se torna necessário, tanto servindo para humanizar quanto para ironizar a figura branca e loura de Jesus Cristo.

De certa forma, quem faz o papel de Deus é Tillery, o médico (igualmente mutilado) que ordena manter Joe vivo, como "objeto de estudo". Tillery decide que Joe nada sente e não pensa - mas como ele poderia saber? A cena em que os médicos estão em volta do corpo despedaçado de Johnny, logo no começo do filme, é feita no ponto de vista da mesa de operações, como se Joe os estivesse vendo. O espectador os vê, portanto, como Joe não pode ver: três homens de branco, máscaras cirúrgicas no rosto, Tillery e suas muletas ao centro, decidindo, como três Parcas (como Cloto, Láquesis e Átropos), a extensão da vida humana de um homem que deveria estar morto. A tomada da cena caracteriza visualmente a tragédia - a hybris da 
ciência e da guerra, associadas, se cumpre em toda a sua extensão dramática.

O filme terminará com uma citação em latim: Dulce et Decorum Est Pro Patria Mori - "doce e honroso é morrer pela pátria". A citação é pior ainda do que aquela que os prisioneiros judeus encontravam estampada nos campos nazistas de concentração. A ironia do diretor, de tão agressiva e óbvia, parecerá "pedestre" àquele crítico, mas ela equivale ao momento em que Johnny e o espectador, sensibilidades despedaçadas, finalmente compreendem o mundo que lhes foi dado "viver".

A ironia equivale a uma blasfêmia - silenciosa.

\section{Referências Bibliográficas}

ARISTÓTELES. Poética. Tradução de Eudoro de Souza. São Paulo: Ars Poetica, 1992.

FLUSSER, V. Pós-história: vinte instantâneos e um modo de usar. São Paulo: Duas Cidades, 1983.

HANSON, P. Dalton Trumbo, Hollywood rebel: a critical survey and filmography. Jefferson. North Carolina: McFarland, 2001.

LEVI, P. É isto um homem? Rio de Janeiro: Rocco, 1997.

LYOTARD, J-F. A condição pós-moderna. Rio de Janeiro: José Olympio, 1998.

MARCONDES, D. Iniciação à história da filosofia. Rio de Janeiro: Jorge Zahar Editor, 2001.

ROSENFELD, A. Texto/contexto II. São Paulo: Perspectiva, 1993.

SCHLINK, B. O leitor. Rio de Janeiro: Nova Fronteira, 1998.

TRUMBO, D. Johnny got his gun. New York: Carol Publishing Group, 1994.

2002.

Johnny s'en va-t-en guerre. DVD Video. Paris: Film Office, 


\section{NOTA}

1 Doutor em Literatura Comparada pela UERJ. Professor adjunto de Teoria da Literatura no Instituto de Letras da UERJ.

\section{ABSTRACT}

\section{A Piece of Meat Which Thinks}

This article studies the fragmentation of History and Science in PostHistory, based on the shattered body of the character Joe from Dalton Trumbo's novel and movie Johnny Got His Gun. In turn, according to the concept of Post-History formulated by Vilém Flusser, Auschwitz and Hiroshima proved to be the logical consequences of (rather than mere accidents in) Western rationality, launching an intense representational crisis, to the point of altering the very notion of progress.

Keywords: Vilém Flusser; Dalton Trumbo; Post-History.

Recebido em: 20/09/2002.

Aprovado em: 12/11/2002. 